\title{
Remembering tropical psychology's departed friend: Charles D. Spielberger
}

Charles D. Spielberger died June 12, 2013 in Tampa assisted by Carol, his wife and his son, Nicholas. He was president of IAAP during the period 1998-2002, became president elect in 1994 and ended his term as past president in 2006. He supervised the 25 ICAP held in Singapore in July 2002 and was actively involved in ICAP1998 held in San Francisco and ICAP 2006 in Athens. He lectured and supervised research on anxiety, stress and anger all around the world.

International Association of Applied Psychology (IAAP) News

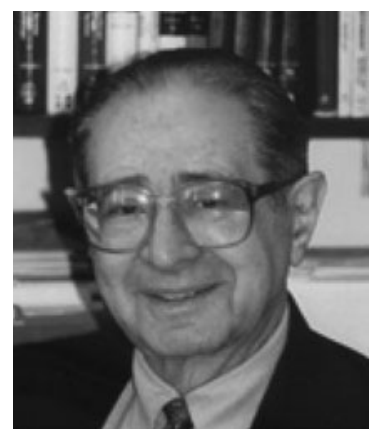

Charles D. Spielberger, $\mathrm{PhD}$

It has been a year now since we lost Professor Spielberger. He was no stranger to congresses, higher education and research in tropical regions: Australia, India, Hong Kong, Japan, Singapore, Spain and Turkey to name a few. This international psychologist, so familiar to most of us, certainly deserves our review for his scientific and professional contributions. A master of diplomacy, and a wise mentor, we can now begin to see the full scope of his influence.

I met him at an international conference in 1982 and worked with him in various capacities since that time, including accreditation guidance for doctoral programmes in psychology, regional and global psychology conference development, and his catalytic imprint on the modern emergence of scientific and applied psychology. As friend and colleague, he never lacked the time and interest to help. For example, he had encouraged us to develop a new collaborative text generated from Singapore with 17 international contributors: Trauma Psychology in Context: International Vignettes and Applications from a Lifespan Clinical-Community Psychology Perspective. In his last year of life and in poor health, soon after he had received his advance copy with our thanks, he sent us a very kind and encouraging email response, well beyond the limits of our expectations, saying the work was a 'unique contribution to our understanding of the traumatic effects of psychological stress and its effects on emotional reactions'. In the manner this exemplifies, he brought out the best in all of us.

Professor Spielberger also had the rare gift of making complex science readily understandable, with the future of scientific psychology compelling on an international stage. Of course, he also did this by example. Here are a few excerpts about his scientific work:

Prior to joining the faculty at the University of South Florida, his long-time professional home, he held faculty appointments at Duke, Vanderbilt (in Nashville) and Florida State University. An incredibly well-funded researcher, he was best known for his creation of the very popular and frequently used State Trait Anxiety Inventory (STAI). This scale has been translated into 66 languages and dialects, and used in more than 15,000 archival studies during the past 30 plus years. He also was the co-author of a number of other very useful tools, such as the State Trait Anger Expression Inventory, which has been translated into eight languages and the Job Stress Inventory. A major figure in advancing our understanding of the linkages between personality and health, he created and directed the Center for Research and Behavioral Medicine and Health Psychology at the University of South Florida. Moreover, he made landmark scholarly contributions related to verbal conditioning, the preventive interventions to alleviate the adverse effects of anxiety on academic performance, and the field of positive psychology. A prolific and gifted writer, and one of the most innovative pioneers in our field, at the time of his death he had over 460 professional publications. What strikes me and others about these writings is that they are crafted in such a reader-friendly fashion, and yet have a sophistication that is rare. Over the years, he received countless awards, including highly coveted lifetime achievement awards, from his university, state and nationally for his scholarly contributions and research prowess.

Nadine Kaslow, President, American Psychological Association, October 2013. 
His body of work is staggering in breadth and depth. I was one of his final graduate students, and our relationship evolved as we then became close colleagues as we worked on numerous scientific projects over a decade. In 2009 he and I completed a five-year research project I spearheaded culminating in the publication of an advanced psychological tool that now has been adapted into eight languages: the State Trait Anger Expression Inventory - Second Edition, Child/Adolescent (Brunner \& Spielberger, 2009). Charlie was one of the most innovative pioneers in the scientific field of personality assessment over the last century. Ilearned from one the best. He was vigilant about the task of conceptualising complex phenomena clearly and in a way that could be soundly measured using brief self-report questionnaires. Charlie inspired me to think about how our field could be used to comprehensively yet concisely assess almost any phenomena that we tackled. And he tackled many! His State Trait Anger Expression Inventory for adults went on to be adapted into over 26 languages, and is likely the most widely used measure of anger in the world today. Many of you have used or heard of the State Trait Anxiety Inventory (STAI), an amazingly brief but useful tool that is also used worldwide and been adapted into over 30 languages. Clearly relevant to consulting psychology, the Job Stress Inventory was also one of the many measures he authored or co-authored. He also made contributions to Positive Psychology through his assessment of curiosity. I fondly remember working with him on Saturdays for years, creating and massaging scientific manuscripts until we arrived at a clear way of capturing the dynamics of complex phenomena such as anger. Charlie taught me a superior way of viewing and analysing human personality that provides a powerful $x$-ray into the human mind. By the end, Charlie likely published nearly 1000 articles and I think up until his death continued to go into the office early and leave late. He truly gave his life to psychology, and that is not a metaphor, it is a fact. Charlie was one of the most highly cited psychologists in the world, and he truly has forwarded our field internationally.

Thomas Brunner (O’Roark, 2013)

There were also fine tributes to the distinguished scientific contributions of Professor Spielberger posted in many international journals, such as the extensive one in the International Psychology Bulletin with testimonials on his scientific and personal contributions from Judith Albino, Rubin Ardila, Thomas M. Brunner, Anna Laura Comunian, Florence Demark, Henry C. Ellis, Sandra Fowler, Machiko Fukuhara, Mary Banks Gregerson, Chok C. Hiew, Howard Kassinove, Paul Lloyd, Rodney L. Lowman, Francis Macnab, Ann Marie O’Roark, Harold Takooshian, Peter Vagg, Danny Wedding and Diane J. Willis. This last excerpt is illustrative:

Assessment theorists and leadership trainers suggest first impressions set the stage for all that follows. My first impression of Charles Spielberger was imprinted while sitting by a stone fireplace in a dark paneled British hotel lobby, listening to his enthusiastic description of his research findings. It was a compelling psychological adventure mystery. Following a workshop Stress Management in Southampton, England on at the annual meeting of the International Council of Psychologists, Charlie talked of scientific sleuthing that began by following clues he discovered in streams of literature developed by psychology's pioneers. Insights from William James, Daniel Berlyne, Anne Anastasia and Janet Spence were advanced by data generated in his research laboratory, in collaboration with doctoral students and international colleagues. Even the brilliant fictional detective Hercule Poirot could not have disentangled any more complex mystery of human interaction than Charles' intriguing discovery of how three vital sign emotions, anxiety, anger and curiosity mediated stress, heart diseases, cancers and executive wellbeing.

(O’Roark, 2013)

Charles Spielberger was a master of organisational psychology, both in developing key collaborative networks for psychologists in tropical regions and as an essential international network presence. His leadership played a key role in building global psychology into a bridge to the twenty-first century, and to the enhanced care of our human family in this new era.

In the Native American Church, the rising of the sun is sometimes greeted with: 'A new day, fresh, untouched. What will we do with it?' Our own new day has begun with the prior advantage of the wise touch of Professor Spielberger. His distinguished contributions deserve honoured inclusion in our evolving story. I am pleased to remember our friend on this anniversary of his passing. I am grateful that he chose to spend so much of his adult life with us creating these memories.

Robert F. Morgan Editor

\section{References}

International Association of Applied Psychology (2013) Charles D. Spielerger. News. http://www.iaapsy.org.

Koslow, N. (2013) A tribute to Charles D. Spielberger, PhD, ABPP. Division Dialogue, October, American Psychological Association.

Morgan, R.F. (2012) Trauma Psychology in Context: International Vignettes and Applications from a Lifespan ClinicalCommunity Psychology Perspective. Santa Cruz, CA: Sentinal/Morgan Foundation.

O’Roark, A. (2013) Charles Spielberger. International Psychology Bulletin (Volume 17, No. 4) Fall. 